\title{
Diastolic Dysfunction
}

National Cancer Institute

\section{Source}

National Cancer Institute. Diastolic Dysfunction. NCI Thesaurus. Code C79547.

Impairment in the filling of the ventricles during diastole. Causes include hypertrophic and restrictive cardiomyopathies, coronary artery disease, chronic high blood pressure, aortic stenosis, and aging. 